\title{
Determinants of use of modern family planning methods: A case of Baringo North District, Kenya
}

\author{
Paul Kisia Malalu ${ }^{1}$, Koskei Alfred ${ }^{1}$, Robert Too ${ }^{1}$, Amon Chirchir ${ }^{2}$ \\ ${ }^{1}$ School of Public Health, Moi University, Eldoret, Kenya \\ ${ }^{2}$ School of Medicine, Moi University, Eldoret, Kenya \\ Email address: \\ pkmalalu@gmail.com (P. Malalu), alfredkoskey@gmail.com (K. Alfred), tookip_2000@yahoo.com (R. Too), \\ akchirchir@yahoo.com (A. Chirchir) \\ To cite this article: \\ Paul Kisia Malalu, Koskei Alfred, Robert Too, Amon Chirchir. Determinants of Use of Modern Family Planning Methods: A Case of \\ Baringo North District, Kenya. Science Journal of Public Health. Vol. 2, No. 5, 2014, pp. 424-430. doi: 10.11648/j.sjph.20140205.18
}

\begin{abstract}
Background: Globally, there is an increasing unmet need for safe and effective family planning services. Most women in Africa, just like in many parts around the world, desire to control both the number and timing of births but lack an effective contraceptive method. The uptake of family planning (FP) services is low in Baringo North District. The overall objective of the study was to describe factors influencing use of modern FP methods. Specific objectives were (i) To investigate the role of knowledge, attitude and practice on the utilization of modern FP methods; (ii) To assess the influence of socio-cultural factors on uptake; and (iii) To associate and correlate the various factors with use of these methods. Methods: This was a cross-sectional descriptive study. The district was stratified according to the four administrative divisions. Total sample size was proportionately allocated to each of the four strata then to the two health facilities that were purposively selected per strata. Women in the reproductive age group that met inclusion criteria attending outpatient service at the selected health facilities were consecutively recruited into the study. Data was collected through interviewer administered questionnaire. Both descriptive and inferential statistics were generated and results considered significant at $95 \%$ confidence level. Results: Of all the 344 respondents, 80.8 percent were aware of Modern FP methods. Pills and injection were most commonly known and used methods, mentioned by 66.2 percent and 64.4 percent of study subjects respectively. Sixty two percent of the respondents approved use of modern contraception while the current use rate was 32.3 percent. The significant predictors of use these methods were the respondents' age, marital status, knowledge on the methods and their side effects, and method approval by self and partner $(p<0.05)$. Conclusion: The low uptake of modern FP methods by women reveals their lack of knowledge on the various methods available, fear of harmful effects, and method approval by self and partner. There is need for reproductive health programs to intensify efforts in improving women's knowledge on modern contraceptive options including their side effects; and encourage constructive partner involvement.
\end{abstract}

Keywords: Family Planning, Knowledge, Attitude, Practice, Socio-Cultural Factors

\section{Introduction}

Successful family planning efforts is essential in alleviation of global poverty by positively contributing to socio-economic development (1). Controlling both the number and timing of births through utilization of contraception is associated with improved maternal and neonatal health outcomes hence contributing to the attainment of Millennium Development Goals (MDGs) $(2,3)$. Reports from around the world reveal that many women suffer from illness and disability resulting from easily preventable pregnancy and child birth related complications (3-6). Family planning (FP) has been associated with positive health effects on children, mothers and the whole family (7). Spacing children can reduce mortality among the under-fives by $10 \%$ and among pregnant mothers by $32 \%(3,5,7,8)$. It empowers women living in poverty through enabling them to have fewer children and reduces competition for available resources at the household $(2,3,5,9)$. Other secondary benefits of FP programs include prevention of sexually transmitted diseases (STDs) and HIV through promoting condom use besides preventing unwanted pregnancies among HIV-positive women hence averting mother-to-child transmission $(3,5$, $10)$. 
The need for family planning services the world over remains unmet $(2,3,8,11)$. Although many women desire to control the number of births, they have no access to effective family planning (6). The use of modern contraception in many countries in Africa is low despite high Total Fertility Rates (TFR). However, majority of women in these parts of the world still wish to have fewer children $(11,12)$. Evidence from studies reveals that high TFRs can be reduced through promotion of family planning $(8,13)$. In Kenya, with a TFR of 4.6 , only $32 \%$ of women of reproductive age use any form of FP method while only $28 \%$ use some modern contraception (12).

Low contraceptive use is attributed to a number of barriers acting at policy, facility, community and individual level (2). At individual level, knowledge of FP methods is crucial. Whereas evidence from a number of studies around the world reveal a near universal knowledge on family planning among the women of the reproductive age group, this has not translated into increased utilization of these methods $(12,14$, 15-17). Low usage has been widely attributed to the negative attitude towards this form of contraception. Specifically, approval/ disapproval of the modern methods by self and partner $(13,16-20)$, fear of harmful effects on health $(12,13$, $17,19,21,22)$, and low levels of education $(13,17,23)$ have been identified to influence use of modern FP methods in Africa, Asia and other parts around the world. This observation suggests that both the women and their partners lack the right information that will aid decision making on use, an argument supported by evidence from related studies that showed increasing knowledge on the methods can result to higher utilization (24). Women and their partners therefore need to be empowered with adequate knowledge particularly on the health effects of modern FP methods to enable them make wise choices (25).

Use of modern FP has also been hindered by perceived lack of support from health care workers (19), socio-cultural factors such as communication between spouses, males' attitude towards contraceptive use and lack of support (13, 1721, 26-32). At the community, views of other women, marital status, desire for more children, myths and mis-conceptions on modern methods and socio-economic status of the women also influence use $(13,17,21,22,28,33)$. The other factor limiting utilization is access since some women who would like to use contraception cannot access it (34-37). Addressing some of these barriers to use modern FP will significantly influence uptake hence positively contribute to socio-economic development.

\section{Materials and Methods}

Area of study: The study was carried out in Baringo North District, in Kenya, which has limited data on determinants of use of modern FP methods. In total, there are 35 functional health facilities in the district- 32 dispensaries, 2 health centres, and one sub district hospital.

Study population: Comprised of the women in the reproductive age group attending outpatient services in the selected facilities. According to the Kenya National Bureau of Statistics (KNBS), the women in the reproductive age group in the district are 24,906 (24.04\% of total population).

Study design: This was a cross- sectional study conducted in September, 2012. Information given by participants focused on key variables aimed at answering the study objectives. These included age, level of education, knowledge on, and use of the available contraceptive methods. Other variables related to the attitude of the respondents to use of modern FP, approval of contraception, couples' discussions on contraceptive use, reasons for non- use and acquisition of the FP products. Socio-cultural variables and infrastructural support were also studied.

Sample size determination: The sample size was determined using Fisher Exact formula. According to KDHS 2008, the prevalence of utilization of modern FP methods among the married women in the target group in Rift Valley Province where Baringo District is found was 34.7 percent. The district target population, N, was 24,906 (24.04 percent of 103,601). The sample size was determined using the formula recommended by fisher et al. (1998).

$$
\mathrm{n}=\frac{\mathrm{Z}^{2} \mathrm{pq}}{d^{2}}
$$

Where;

$Z=1.96(Z$ score corresponding to $95 \%$ confidence interval).

$\mathrm{P}=0.347 \quad 0.347 \quad$ (prevalence of use of modern contraception)

$\mathrm{q}=0.653(1-\mathrm{p})$

$d=0.05$ (Sampling error /the margin of error $(5 \%)$ that can be accepted in this study).

$\mathrm{N}=24,906$ (Target population)

$$
\mathrm{n}=\frac{1.96^{2} \times 0.347 \times 0.653}{0.05^{2}}=343.4
$$

The sample size was a minimum of 344 women of reproductive age.

Sampling techniques: Due to the geographical diversity in the district, a stratified sampling procedure was employed. The district was stratified according to the four divisions representing four strata, namely, Kabartonjo, Barwessa, Kipsarman and Bartabwa. The sample size of 344 respondents was then proportionately allocated to the four strata based on the strata's total target population as follows: Kabartonjo Division, 140 respondents; Barwessa Division, 82; Bartabwa Division, 45; and Kipsarman Division, 77. Two facilities per division (stratum) with the highest catchment population (expected to have high outpatient attendance) were selected through purposive sampling. The number of respondents per stratum was then proportionately allocated to each of the two selected facilities. The participants recruited into the study were women aged 15-49 years, willing to participate and had given consent (or given assent for those below 18 years), and were attending outpatient services except in the 
reproductive health clinics. Respondents were consecutively recruited into the study until the allocated sample size was achieved.

Data collection procedure: A pilot study was carried out at Huruma Health Centre and Uasin Gishu District Hospital to pre-test the questionnaire. During the actual data collection, subjects were interviewed by research assistants through use of a questionnaire that had been validated in a pilot study.

Data management and analysis: Filled questionnaires were checked for completeness and coded by the researcher. Frequencies were generated for categorical variables and summary measures for continuous variables. Cross tabulations (chi-square) were computed to establish relationships among the variables. Regression and correlation analysis were also done. Test results were considered significant at 95\% confidence level.

Ethical Considerations: The research proposal was approved by the Institutional Research and Ethics Committee (IREC) of Moi University for approval. The District Medical Officer of Health for Baringo North and the health facility management approved the study. Confidentiality of the participants was maintained through coded questionnaires.

\section{Results}

\subsection{Socio-Demographic Factors}

A total of 344 women of reproductive age were studied. The mean age of respondents was $28.7 \pm 7.5$ with a median of $28(23,34)$. Of the 247 respondents that were married, their mean age at marriage was $21.1 \pm 3.2$ and a median of $20(18$, 23). The other demographics were as indicated in table 1.

Table 1. Socio-demographic characteristics of the respondents $(n=344)$

\begin{tabular}{ll}
\hline Characteristic & N (\%) \\
\hline Level of education & $14(4.1)$ \\
None & $133(38.7)$ \\
Primary & $153(44.5)$ \\
Secondary & $44(12.8)$ \\
Tertiary & \\
Marital status & $86(25.0)$ \\
Singe & $247(71.8)$ \\
Married & $7(2.0)$ \\
Divorced/ separated & $4(1.2)$ \\
Widowed & \\
Main source of income & $46(13.4)$ \\
From employment & $165(48.0)$ \\
Business & $46(13.4)$ \\
Remittance from kin & $82(23.8)$ \\
Farming & $5(1.5)$ \\
Others & \\
\hline
\end{tabular}

\subsection{Knowledge, Attitude and Use of Modern Family Planning}

Awareness on family planning (FP) was almost universal with 98 percent of respondents confirming being aware. The main source of information or messages on FP was through the health workers (74.8 percent). Other sources are as indicated in table 2 .
Table 2. Knowledge on Family Planning methods

\begin{tabular}{ll}
\hline Characteristic & N (\%) \\
\hline Source of information on FP $(\mathbf{N}=\mathbf{3 4 4})$ & \\
Health care workers & $257(74.7)$ \\
Radio & $158(45.9)$ \\
Friends and Kin & $90(26.2)$ \\
TV & $56(16.4)$ \\
Others & $44(12.8)$ \\
Know any Method $(\mathbf{N}=\mathbf{3 4 4})$ & \\
Yes & $278(80.8)$ \\
No & $66(19.2)$ \\
Know any specific method $(\mathbf{N}=\mathbf{2 7 8})$ & \\
Pills & $184(66.2)$ \\
Injections & $179(64.4)$ \\
Male condoms & $71(25.5)$ \\
Implants & $42(15.1)$ \\
Others & $49(17.6)$ \\
\hline
\end{tabular}

The pills and injections were the most widely known among study participants. A majority of the respondents (61.6 percent) approved use of these methods (table 3). Reasons given for approval were diverse. Most of them (62.3 percent) believed use of modern contraception helps to maintain standards of living, 45.3 percent indicated that it limits family and reduces expenditure, 25.5 percent said it makes families small and happy, while 6.6 percent reported that it protects mother's health. Among the thirty eight percent of all respondents who did not approve use of modern FP, a majority (98.4 percent) feared harmful side effects. Fifty percent of all the participants had or their partner had ever used modern FP methods with the most commonly used options being injection (56.5 percent), pills (30.5 percent), and male condom (18.6 percent). The long acting and permanent methods which were least known were similarly least used.

Table 3. Approval of use of Modern FP

\begin{tabular}{ll}
\hline Characteristic & N (\%) \\
\hline $\begin{array}{l}\text { Approve use of modern FP }(\mathbf{N}=\mathbf{3 4 4}) \\
\text { Yes }\end{array}$ & $212(62.0)$ \\
No & $130(38.0)$ \\
Ever used modern FP $(\mathrm{N}=342)$ & \\
Yes & $177(51.8)$ \\
No & $165(48.2)$ \\
Know any Method $(\mathbf{N}=\mathbf{3 4 4})$ & \\
Yes & $278(80.8)$ \\
No & $66(19.2)$ \\
Current use $(\mathbf{N}=\mathbf{3 4 4})$ & \\
Yes & $111(32.3)$ \\
No & $233(67.7)$ \\
Commonly used Modern FP $(\mathbf{N}=\mathbf{1 7 7})$ & \\
Pills & $54(30.5)$ \\
Injections & $100(56.5)$ \\
Male Condoms & $33(18.6)$ \\
Implants & $12(9.6)$ \\
Others & $31(17.5)$ \\
\hline
\end{tabular}

Various factors considered before choosing a particular method were given by the study subjects. Approval by partner (40.6 percent), side effects (35.8 percent), and accessibility (26.4 percent) were the major considerations.

Other factors considered were acceptability of the method (18.4 percent), convenience in using (14.6 percent) and cost 
(13.7 percent). Approval by friends (2.8 percent) and knowledge on the methods ( 9 percent) were considered least in this group.

The current use of modern FP among all the respondents in the study was low (32.3 percent). On sources of modern contraception, a majority (92.1 percent) of those who had ever used got this service at the health facility.

\subsection{Role of Socio- cultural Factors in Use of Modern Family Planning Methods}

Assessment of socio-cultural factors, measured on a likert scale, revealed that on average, the respondents who had ever used modern FP methods reported that cultural and religious beliefs, suggestions and approval from friends, and village talk did not influence their decision to use (table 4). Neither did they think that traditional methods were better. However, they agreed that approval from their partners influenced their decision, and that choice of a contraceptive method was a couple's responsibility. Seventy nine percent of the respondents who had ever used modern FP confirmed having discussed the choice and use with their partner, and many revealed that their partners were supportive. A majority ( 95 percent) of those who did not have discussions with their partners indicated that their partners had no knowledge of their use of these methods. The injection was the preferred method in this group.

Table 4. Views on influence of socio-cultural factors on use of FP methods

\begin{tabular}{|c|c|c|c|c|c|c|}
\hline View & $\begin{array}{l}\text { Strongly agree } \\
\text { n (\%) }\end{array}$ & $\begin{array}{l}\text { Agree some- } \\
\text { what n (\%) }\end{array}$ & Neutral n (\%) & $\begin{array}{l}\text { Disagree } \\
\text { some-what n (\%) }\end{array}$ & $\begin{array}{l}\text { Disagree } \\
\text { strongly n (\%) }\end{array}$ & $\begin{array}{l}\text { Mean on } \\
\text { likert scale } \\
\end{array}$ \\
\hline Cultural beliefs & $33(18.6)$ & $31(17.5)$ & $7(4)$ & $12(6.8)$ & $94(53.1)$ & $3.6 \pm 1.7$ \\
\hline Religious beliefs & $9(5.1)$ & $15(8.5)$ & $11(6.2)$ & $18(10.3)$ & $124(70.1)$ & $4.3 \pm 1.2$ \\
\hline Friends approval & $31(17.5)$ & $55(31.4)$ & $21(11.9)$ & $6(3.4)$ & $64(36.2)$ & $3.1 \pm 1.6$ \\
\hline Rumors/village talk & $21(11.9)$ & $53(29.9)$ & $23(13)$ & $11(6.2)$ & $69(39)$ & $3.3 \pm 1.5$ \\
\hline Partner approval & $91(51.4)$ & $40(22.6)$ & $7(4)$ & $7(4)$ & $32(18.1)$ & $2.2 \pm 1.5$ \\
\hline Prefer traditional method & $6(3.4)$ & $10(5.6)$ & $16(9)$ & $17(9.6)$ & $128(72.3)$ & $4.4 \pm 1.1$ \\
\hline Partners to choose method jointly & $88(49.7)$ & $36(20.3)$ & $20(11.3)$ & $14(7.9)$ & $19(10.7)$ & $2.1 \pm 1.4$ \\
\hline
\end{tabular}

\subsection{Association of Demographic and Socio-Economic Variables with Uptake of Modern FP Methods}

In bivariate analysis, age, education level, marital status, source of income and desire to have children were significantly associated with use of modern FP methods $(\mathrm{p}<0.005)$ as indicated in table 5. Those who desired to have more children were less likely to use contraception. Knowing any FP method or side effects and approval of use were significantly associated with uptake $(\mathrm{p}<0.05)$ as indicated in table 6 .

Table 5. Association between demographic factors with use of modern FP methods

\begin{tabular}{|c|c|c|c|c|}
\hline \multirow{2}{*}{ Characteristic } & \multicolumn{2}{|c|}{ Ever use of modern FP Methods } & \multirow{2}{*}{ chi-sq/z-value } & \multirow{2}{*}{ p-value } \\
\hline & Yes & No & & \\
\hline Age & $30(25,35)$ & $25(21,31)$ & 4.365 & $<0.001^{1}$ \\
\hline Income (Ksh) & $4500(1800,75000)$ & $3500(2000,6000)$ & 1.835 & $0.067^{1}$ \\
\hline Number of children & $4(2,5)$ & $2(1,3)$ & 0.194 & $0.846^{1}$ \\
\hline Distance to nearest facility $(\mathrm{Km})$ & $2(1,3)$ & $2(1,3)$ & 1.137 & $0.256^{1}$ \\
\hline \multicolumn{5}{|l|}{ Education level } \\
\hline None & $2(15,4)$ & $11(84.6)$ & \multirow{4}{*}{11.397} & \multirow{4}{*}{$<0.001^{2}$} \\
\hline Primary & $63(47.4)$ & $70(52.6)$ & & \\
\hline Secondary & $85(54.6)$ & $69(45.4)$ & & \\
\hline Tertiary & $29(65.9)$ & $15(34.1)$ & & \\
\hline \multicolumn{5}{|l|}{ Marital status } \\
\hline Single & $26(30.2)$ & $60(69.8)$ & \multirow{3}{*}{28.233} & \multirow{3}{*}{$<0.001$} \\
\hline Married & $147(60.2)$ & $97(39.8)$ & & \\
\hline Others & $4(36.4)$ & $7(63.6)$ & & \\
\hline \multicolumn{3}{|l|}{ Main source of income } & \multirow{6}{*}{20.551} & \multirow{6}{*}{$<0.001^{2}$} \\
\hline Employment & $35(76.1)$ & $11(23.9)$ & & \\
\hline Business & $86(52.1)$ & $79(47.9)$ & & \\
\hline Farming & $40(50.6)$ & $39(49.4)$ & & \\
\hline Remittance from Kin & $16(34.8)$ & $30(65.2)$ & & \\
\hline Others & $0(0)$ & $4(100)$ & & \\
\hline \multicolumn{3}{|l|}{ Desire to have children } & \multirow{3}{*}{8.827} & \multirow{3}{*}{$0.003^{1}$} \\
\hline Yes & $99(45.8)$ & $117(54.2)$ & & \\
\hline No & $77(62.6)$ & $46(37.4)$ & & \\
\hline
\end{tabular}

P- values: $1=$ Pearson, $2=$ Fisher's Exact 
Kenya

Table 6. Association of knowledge on modern FP methods with use

\begin{tabular}{lllll}
\hline \multirow{2}{*}{ Factor } & \multicolumn{2}{l}{ Ever use of modern FP } & chi-sq/z-value & p-value \\
\cline { 2 - 3 } Ever heard of FP & $175(51.9)$ & No & 0.281 & 0.6751 \\
Yes & $2(40)$ & $162(48.1)$ & & \\
No & $170(61.2)$ & $3(60)$ & 52.533 & $<0.001^{1}$ \\
Know any FP & $7(10.9)$ & $108(38.8)$ & \\
Yes & $138(67.3)$ & $57(89.1)$ & 49.639 & $<0.001^{1}$ \\
No & $39(28.5)$ & $67(32.7)$ & \\
Know any side effect & $139(65.6)$ & $98(71.5)$ & & \\
Yes & $38(29.2)$ & $73(34.4)$ & 42.609 & $<0.001^{1}$ \\
No & & $92(70.8)$ & \\
Approve use of modern FP & & & \\
Yes & & & \\
No & & & \\
\hline
\end{tabular}

P- values: $1=$ Pearson, $2=$ Fisher's Exact

In a multivariate analysis, and controlling for all other variables, age of the respondent, knowledge on any modern FP method and its side effects, approval of use methods, and marital status were significant predictors of utilization of these methods $(p<0.05)$ (table 7). A unit increase in age increased the chances of using modern contraception by seven percent; those who knew any method and side effects were almost seven times and two times respectively more likely to use these methods. Among the married women, the likelihood of uptake of FP was almost three times than among single women.

Table 7. Multiple logistic regression model

\begin{tabular}{lllll}
\hline \multirow{2}{*}{ Variable } & Sig & Odd & \multicolumn{2}{l}{$\mathbf{9 5 . 0} \%$ CI for OR } \\
\cline { 4 - 5 } & $\mathbf{0 . 2 1}$ & Ratio & Lower & Upper \\
\hline Age & 0.021 & 1.067 & 1.01 & 1.127 \\
$\begin{array}{l}\text { Education } \\
\text { None }\end{array}$ & 0.194 & 0.265 & 0.036 & 1.963 \\
$\begin{array}{l}\text { Primary } \\
\text { Secondary }\end{array}$ & 0.108 & 0.445 & 0.165 & 1.195 \\
$\begin{array}{l}\text { Desire to have } \\
\text { children (Yes) }\end{array}$ & 0.314 & 0.644 & 0.274 & 1.516 \\
$\begin{array}{l}\text { Know any modern FP } \\
\text { method }\end{array}$ & 0.41 & 0.742 & 0.365 & 1.508 \\
$\begin{array}{l}\text { Approve use of } \\
\text { modern FP methods }\end{array}$ & 0.001 & 6.649 & 2.278 & 19.403 \\
$\begin{array}{l}\text { Yes) } \\
\text { Marital status }\end{array}$ & 0.00 & 3.85 & 2.093 & 7.083 \\
$\begin{array}{l}\text { Married } \\
\text { Singles }\end{array}$ & 0.001 & 3.469 & 1.614 & 7.454 \\
$\begin{array}{l}\text { Average income } \\
\text { Constant }\end{array}$ & 0.543 & 0.62 & 1.133 & 2.889 \\
\hline
\end{tabular}

\section{Discussion}

The purpose of this study was to identify factors that influence utilization of modern FP methods in Baringo North District. The findings revealed that knowledge of different types of methods; side effects and approval of modern contraception were the major predictors for use of modern family planning $(\mathrm{P}<0.05)$.

Evidence from this study revealed that although awareness of family planning was very high, this did not translate into high utilization of modern contraception. This is despite many respondents confirming receiving messages on FP from a variety of sources. The low usage of FP among the respondents could probably be because they do not have adequate information that would aid in choosing an appropriate contraceptive method. This also partially explains the fear of side effects. The gap in knowledge is further illustrated by the narrow range of options for FP that the respondents knew or had ever used. The pills and injections were the most mentioned and the most used while the converse was true for the long acting and permanent methods. Knowledge of side effects was also a major consideration before choosing any particular method. Reports from other studies in India, Kenya, Ethiopia, Ghana and Nigeria have similarly revealed inadequate information on available options, low usage and fears on health effects as barriers to use $(12,14-17,19,22-25)$. There is an urgent need for countries to educate women on the various available methods and more specifically on their side effects if they (countries) are to effectively increase uptake of modern contraception. This recommendation has been made by Muia et al. in a past but related study (25). Doing so will positively contribute to reduction of the TFR rates and lower maternal and childhood mortality associated with unplanned pregnancies

Approval of modern FP methods by the women was also a major factor influencing their use. The findings revealed that most of the women who approved use of these methods (61.6 percent) confirmed having used them, just as reported in a study in Ethiopia (14). Moreover, many of the women who did not approve use of these contraceptives largely feared harmful effects. This further illustrates the need to educate women on the health effects of modern contraception.

On further assessment of socio-cultural factors, partner discussion and approval emerged as a key socio-cultural consideration in choosing and utilizing contraception. This study revealed that spousal communication encouraged approval and uptake since most of the women (79 percent) who reported having discussed with their partners actually used some method (partners were reported to be supportive) compared to those who did not. A majority (95 percent) of those who did not have discussions with their partners indicated that their partners had no knowledge of use. The 
injection was the preferred method in the latter group, maybe because the partner would not know of its use. This findings are consistent with reports in other studies on influence of socio- cultural factors on choice and uptake of modern FP $(14,16,18,20,21,26-32)$, and confirm the need for having constructive partner discussions as a way of encouraging contraception uptake. However, they contrast with those in turkey where cultural beliefs greatly influenced use of contraception (19).

An association of socio-demographic variables revealed that age, level of education, marital status, source of income and desire to have children were significantly associated with modern FP use $(\mathrm{P}<0.05)$, similar to findings in India and Ghana $(17,23)$.

\section{Conclusion and Recommendations}

This study reveals that knowledge on the various methods, fear of harmful effects, and approval of use by self and partner were the major predictors of uptake of modern contraceptive methods. These factors were also identified as major barriers to use among the women who had never used such forms of family planning. The low utilization of modern contraception despite a near universal awareness through various forums confirms that the women need more knowledge on FP methods that will focus on available options and their effects on health. Lack of adequate knowledge is confirmed by the few options that are known and ever used by the women, the fear of side effects as a major consideration when choosing a method and as barrier to use among those who have never used. Partner communication is also crucial in adopting a birth control option as it plays a major role while choosing a method. Women who discussed choice and use of contraceptive method were more likely to use compared to those who did not.

The study recommends that reproductive health programs need to intensify efforts in improving women's knowledge of modern FP methods. They should also encourage constructive partner communication and engagement in order to increase modern FP uptake. There is also need to re-evaluate the current integrated maternal child health and family planning services to directly, actively and effectively accommodate male partners. Further research into the male partner views on family planning; psychosocial and cultural determinants of non-use; and barriers to the use of modern contraceptive methods among both men and women is proposed.

\section{References}

[1] Successful Family Planning Efforts Essential to Alleviating Global Poverty, Elevating Women, Opinion Piece. New York Times 2009 April 06. Retrieved on 06/06/2010; from: http://www.medicalnewstoday.com/articles/145330.php

[2] Cleland J, Bernstein S, Ezeh A, Faundes A, Glasier A, Innis J. Family planning: the unfinished agenda. Lancet. 2006 Nov 18; 368(9549):1810-27.
[3] UNFPA. Global Need for Family planning (no date). Retrieved on 06/06/2010; from: http://www.unfpa.org/rh/planning/mediakit/docs/new_docs/ sheet1-english.pdf

[4] Hogan MC, Foreman KJ, Naghavi M, Ahn SY, Wang M, Makela SM, Lopez AD, Lozno R, Murray CJL. Maternal mortality for 181 countries, 1980-2008: a systematic analysis of progress towards Millennium Development Goal 5. Lancet 2010, 375(9726):1609-11623.

[5] UNFPA. Maternal Health in Africa. 2013

[6] UNFPA: Contraceptives save lives. 2012

[7] Darroch JE, Singh S, Nadeau J: In Brief (No.5) New York. In Contraception: an investment in lives, health and development. New York: Guttmacher Institute and UNFPA; 2008.

[8] Cleland JG, Ndugwa RP, Zulu EM. Family planning in sub-Saharan Africa: progress or stagnation? Bulletin of the World Health Organization 2011; 89:137-143.

[9] UNFPA: Ensuring that Every Pregnancy is Wanted (no date). Retrieved on 06/06/2010; from: http://www.unfpa.org/rh/planning.htm

[10] USAID: Repositioning Family Planning in Sub- Saharan Africa (August 2006). Retrieved on 06/06/2010. www.usaid.gov/our_work/global_health//pop/techareas/repo sitioning/briefs/repo_subafr.pdf

[11] Westoff, CF. Unmet Need for Modern Contraceptive Methods. DHS Analytical Studies No. 28. Calverton, Maryland, USA: ICF International, 2012.

[12] Kenya National Bureau of Statistics: Kenya Demographic Health Survey (2008.)

[13] World Bank. World Development Indicators. Washington, DC. 2009.

[14] Gizaw A, Regassa N. Family planning service utilization in Mojo town, Ethiopia: A Population based study. Journal of Geography and Regional Planning Vol. 4(6), pp. 355-363, June 2011.

[15] Aninyei, IR, Onyesom I, Ukuhor HO, Uzuegbu, UE, Ofili MI, Anyanwu EB. Knowledge, Attitude to modern family planning methods in Abraka communities, Delta state, Nigeria. East African Journal of Public Health. 2008 April;5(1).pp10-11

[16] Rao GR, Moulasha K, Sureender S. Knowledge, attitude and practice of family planning among fishermen in Tamil Nadu. The Journal of Family Welfare. 1993 September;39(3). p. 50-54.

[17] Aryeetey R, Kotoh AM, Hindin, MJ. Knowledge, Perceptions and Ever Use of Modern Contraception among Women in the Ga East District, Ghana. African Journal of Reproductive Health. 2010 December; 14(4):27.

[18] Lasie A, Backer S. Husband- Wife Communication about Family Planning and Contraceptive Use in Kenya. International Family Planning Perspectives. 1997; 23: $15-20 \& 33$.

[19] Karavus M, Cali S, Kalaca S, Cebeci D. Attitudes of married individuals towards oral contraceptives: a qualitative study in Istanbul, Turkey. J Fam Plann Reprod Health Care. 2004 Apr;30(2):95-8 
[20] Were EO,Karanja JK. Attitudes of males to contraception in a Kenyan rural population. East Afr Med J. 1994 Feb; 71(2):106-9.

[21] Hall MAK, Stephenson RB, Juvekar S. Social and logistical barriers to the use of reversible contraception among women in a rural Indian village. J Health Popul Nutr. 2008 Jun; 26(2):241-50.

[22] Agha S. Intentions to use contraceptives in Pakistan: implications for behavior change campaigns. BMC Public Health. 2010 Aug 2;10:450

[23] Kumar M, Meena J, Sharma S, Poddar A, Dhalliwal V. Contraceptive Use Among Low-Income Urban Married Women in India. J Sex Med. 2010 Oct 4;1-7

[24] Tang S, Tian L, Cao WW, Zhang K, Detels R, Li VC. Improving reproductive health knowledge in rural china--a web-based strategy. J Health Commun. 2009 Oct-Nov; 14(7):690-714

[25] Muia E, Ellertson C, Lukhando M, Flul B, Clark S, Olenja J. Emergency contraception in Nairobi, Kenya: knowledge, attitudes and practices among policymakers, family planning providers and clients, and university students. Contraception. 1999 Oct; 60(4):223-32.

[26] Ogunjuyigbe PO, Ojofeitimi EO, Liasu A. Spousal communication, changes in partner attitude, and contraceptive use among the Yorubas of southwest Nigeria. Indian J Community Med. 2009 Apr; 34(2):112-6.

[27] Hardee-cleaveland K. Communication key for family planning. Netw Res Triangle Park N C. 1992 Aug;13(1):13

[28] Samandari G, Speizer IS, O'Connell K. The role of social support and parity in contraceptive use in Cambodia. Int Perspect Sex Reprod Health. 2010 Sep;36(3):122-31.

[29] Wambui T, Ek AC, Alehagen S. Perceptions of family planning among low-income men in Western Kenya. Int Nurs Rev. 2009 Sep; 56(3):340-5.

[30] S A Khasiani. Family planning knowledge, attitudes and practices among health centre personnel in Western Province of Kenya. Journal of obstetrics gynaecology of Eastern and Central Africa (1991). Volume: 9, Issue: 1, Pages: 30-36

[31] Kamal N. Influence of family head's reproductive behaviour on the use of modern contraceptive methods by other members of the family in rural Bangladesh. J Biosoc Sci. 1996 Jul $28 ;(3): 297-303$

[32] Kamal N. The influence of husbands on contraceptive use by Bangladeshi women. Health Policy Plan. 2000 Mar; 15(1):43-51.

[33] Lakew y, Reda AA, Tamene H, Benedict S, Deribe K. Geographical variation and factors influencing modern contraceptive use among married women in Ethiopia: evidence from a national population based survey. Reproductive Health 2013, 10:52

[34] Lee RB, Nacionales LP, Pedroso L. The influence of local policy on contraceptive provision and use in three locales in the Philippines. Reprod Health Matters. 2009 Nov; 17(34):99-107.

[35] Douthwaite M, Ward P. Increasing contraceptive use in rural Pakistan: an evaluation of the Lady Health Worker Programme. Health Policy Plan. 2005 Mar; 20(2):117-23.

[36] Kamal SM, Islam MA. Contraceptive use: socioeconomic correlates and method choices in rural bangladesh. Asia Pac J Public Health. 2010 Oct; 22(4):436-50.

[37] Tawye Y, Jotie F, Shigu T, Ngom P, Maggwa N. The potential impact of community-based distribution programmes on contraceptive uptake in resource-poor settings: evidence from Ethiopia. Afr J Reprod Health. 2005 Dec; 9(3):15-26. 